OPEN ACCESS

Edited by:

Liping Liu,

Capital Medical University, China

Reviewed by:

Christoph Stretz,

Yale University, United States

Sebastian Pollandt,

Rush University, United States

*Correspondence:

Wen Jiang

jiangwen@fmmu.edu.cn

Specialty section:

This article was submitted to Neurocritical and Neurohospitalist

Care,

a section of the journal

Frontiers in Neurology

Received: 06 July 2018 Accepted: 18 September 2018

Published: 08 October 2018

Citation:

Yuan F, Yang F, Jia R, Li W, Jiang Y, Zhao J and Jiang W (2018) Multimodal Predictions of Super-Refractory Status Epilepticus and Outcome in Status Epilepticus Due to Acute Encephalitis.

Front. Neurol. 9:832. doi: 10.3389/fneur.2018.00832

\section{Multimodal Predictions of Super-Refractory Status Epilepticus and Outcome in Status Epilepticus Due to Acute Encephalitis}

\author{
Fang Yuan, Fang Yang, Ruihua Jia, Wen Li, Yongli Jiang, Jingjing Zhao and Wen Jiang*
}

Department of Neurology, Xijing Hospital, Fourth Military Medical University, Xi'an, China

Objective: Status epilepticus (SE) is one of the most critical symptoms of encephalitis. Studies on early predictions of progression to super-refractory status epilepticus (SRSE) and poor outcome in SE due to acute encephalitis are scarce. We aimed to investigate the values of neuroimaging and continuous electroencephalogram (EEG) in the multimodal prediction.

Methods: Consecutive patients with convulsive SE due to acute encephalitis were included in this study. Demographics, clinical features, neuro-imaging characteristics, medical interventions, and anti-epileptic treatment responses were collected. All the patients had EEG monitoring for at least $24 \mathrm{~h}$. We determined the early predictors of SRSE and prognostic factors of 3-month outcome using multivariate logistic regression analyses.

Results: From March 2008 to February 2018, 570 patients with acute encephalitis were admitted to neurological intensive care unit (N-ICU) of Xijing hospital. Among them, a total of 94 patients with SE were included in this study. The percentage of non-SRSE and SRSE were 76.6 and $23.4 \%$. Cortical or hippocampal abnormality on neuroimaging $(p=0.002$, OR 20.55, 95\% Cl 3.16-133.46) and END-IT score $(p<0.001$, OR 4.07, $95 \% \mathrm{Cl} 1.91-8.67)$ were independent predictors of the progression to SRSE. At 3 months after N-ICU discharge, 56 (59.6\%) patients attained good outcomes, and 38 (40.4\%) patients had poor outcomes. The recurrence of clinical or EEG seizures within $2 \mathrm{~h}$ after the infusion rate of a single anesthetic drug $>50 \%$ proposed maximal dose $(p=0.044$, OR $4.52,95 \% \mathrm{Cl} 1.04-19.68)$, tracheal intubation $(p=0.011$, OR 4.99, 95\% Cl 1.37-11.69) and emergency resuscitation $(p=0.040$, OR 9.80, 95\% 1.11-86.47) predicted poor functional outcome.

Interpretation: Initial neuro-imaging findings assist early identification of the progression to SRSE. Continuous EEG monitoring contributes to outcome prediction in SE due to acute encephalitis.

Keywords: status epilepticus, encephalitis, super-refractory status epilepticus, neuroimaging, continuous electroencephalogram, multimodal prediction 


\section{INTRODUCTION}

Encephalitis is an inflammatory process of the brain, with an incidence of 3.5-12.6 cases per 100,000 patient-years worldwide $(1,2)$. Patients with acute encephalitis typically present with acute onset of fever, impaired consciousness, headache, seizures, or new onset of focal neurologic deficits (3). Acute encephalitis is a severe form of neurological illnesses that usually requires intensive care for monitoring and treatment. Reported mortality rates range between 7 and $18 \%$, and up to $56 \%$ of survivors suffer from severe disability (4-7).

Status epilepticus (SE) is one of the most common neurological symptoms of encephalitis, occurring in $18.5 \%$ cases of acute encephalitis (5). Previous studies suggested that younger age, coma, cortical lesions on neuroimaging, and nonneurologic organ failure were risk factors for the incidence of SE in patients with encephalitis $(8,9)$. SE due to acute encephalitis is a critical condition that is strongly associated with higher refractoriness $(10,11)$. It often evolves to super-refractory status epilepticus (SRSE) and consequently results in higher mortality (5, 10, 11). Early identifications of the patients with higher risks of progression to SRSE and poor outcomes will help clinicians orient treatment strategies and may improve the outcomes of SE in acute encephalitis.

Given the current paucity of studies regarding the aforementioned problems, we conducted a 10-year retrospective study in the neurological intensive care unit (N-ICU) to investigate the contributions of brain magnetic resonance imaging (MRI) and electroencephalogram (EEG) monitoring in the multimodal predictions of progression to SRSE and 3-month poor outcome in SE due to acute encephalitis.

\section{MATERIALS AND METHODS}

\section{Design and Setting}

This study was based on a prospective database of acute encephalitis patients in N-ICU at Xijing hospital, China, a tertiary academic hospital. It was registered in ClinicalTrials.gov (NCT02278016) and approved by the ethics committee of the Xijing Hospital (KY20140916-3). We adhered to Chinese laws and the Declaration of Helsinki.

\section{Patients}

From March 2008 to February 2018, all consecutive patients with convulsive SE due to acute encephalitis and aged 13 years or older were included in this study. Acute encephalitis was defined as encephalopathy (altered mental status lasting $\geq 24 \mathrm{~h}$ with no alternative cause identified), and three or more of the following: documented fever $\geq 38^{\circ} \mathrm{C}$ within the $72 \mathrm{~h}$ before or after presentation; generalized or partial seizures not fully attributable to a preexisting seizure disorder; new onset of focal neurologic findings; CSF WBC count $\geq 5 /$ cubic $\mathrm{mm}$; abnormality of brain parenchyma on neuroimaging (suggestive of encephalitis); abnormal electroencephalogram (EEG) findings (consistent with encephalitis) (3). According to the operational definition proposed by International League Against Epilepsy, we defined convulsive SE as $5 \mathrm{~min}$ or more of continuous motor seizure activity or recurrent seizure activity without regaining full consciousness between episodes (12).

\section{Management}

The management of SE adhered to related guidelines (1315). Benzodiazepines were administered as the first-line agents, followed by intravenous sodium valproate or phenobarbital sodium to treat persisting SE. In patients who were resistant to both first-line and second-line agents, midazolam or propofol was administered continuously as the third-line treatment. The initial loading dose of midazolam was $0.2 \mathrm{mg} / \mathrm{kg}$, and the proposed maximal dose (PMD) of maintenance infusion rate for midazolam was $0.4 \mathrm{mg} / \mathrm{kg} / \mathrm{h}(14,15)$. The initial loading dose of propofol was $2 \mathrm{mg} / \mathrm{kg}$, and the PMD of maintenance infusion rate of propofol was $10 \mathrm{mg} / \mathrm{kg} / \mathrm{h}$ (14, 15). When a single anesthetic with PMD failed to control SE, simultaneous polytherapy of continuous infusion of anesthetics (CIVADs) was administered (16-19). All the SE patients received bedside video-EEG monitoring for at least $24 \mathrm{~h}$ with an array of 20 scalp electrodes (Solar $2000 \mathrm{~N}$, Solar Electronic Technologies Co., Ltd., Beijing, China) to guide anti-seizure treatments and detect non-convulsive epileptic seizures.

\section{Data Collection}

The following measures were recorded and assessed: (1) variables before N-ICU admission including time from onset of encephalitis to N-ICU admission, time from onset of encephalitis until diagnosis of SE, seizures before admission, and history of epilepsy; (2) severity of illness including Glasgow Coma Scale (GCS), Status Epilepticus Severity Score (STESS) (20), and END-IT score (11); (3) encephalitis etiology diagnosed according to related guidelines and consensuses (21-26); (4) complication of non-convulsive status epilepticus (NCSE) in coma; (5) brain image (abnormal brain MRI findings were defined as hypointensity on T1WI and hyperintensity on T2WI and FLAIR); (6) N-ICU managements including length of EEG monitoring, number of intravenous antiepileptic drugs (IV AEDs), use of CIVADs, CIVAD > 50\% PMD, CIVADs changed, immune therapies (including steroids, immunoglobulins, plasma exchange, and rituximab), tracheal intubation, use of vasopressors, and emergency resuscitation; (7) antiepileptic treatment responses including clinical or EEG seizures within $2 \mathrm{~h}$ after CIVAD, clinical or EEG seizures within $2 \mathrm{~h}$ after CIVAD $>50 \%$ PMD, breakthrough seizures, and withdrawal seizures. NCSE in coma was defined as a type of SE, which happened in comatose patients, without motor movements or with manifestations of continuous and rhythmic phenomenon of more subtle motor twitches of the eyelid, jaw, face, trunk or extremities $(12,16)$. Emergency resuscitation was defined as administering emergency measures to sustain the vital functions of a person in severe respiratory and circulatory failure, malignant arrhythmia, or cardiac arrest. CIVAD was changed when a second CIVAD (monotherapy) was used because of the poor seizure control. Breakthrough seizures were defined as any clinical or EEG seizures occurring after the 
first $6 \mathrm{~h}$ of the initial CIVAD treatment; withdrawal seizures were defined as any clinical or EEG seizures occurring within $48 \mathrm{~h}$ after initially discontinuing or tapering the CIVAD $(27,28)$. Clinical seizures were defined as any epileptic seizures with perceivable motor movements. EEG seizures were defined as any spikes, sharp waves, or sharp and slow wave complexes lasting for $\geq 10 \mathrm{~s}$ at either a frequency of at least three per second or a frequency of at least one per second with clear evolution in frequency, morphology, or location $(28,29)$.

\section{Outcomes}

Refractory status epilepticus (RSE) was defined as SE that continued despite treatment with benzodiazepines and one antiepileptic drug (30). SRSE was defined as SE that continued or recurred $24 \mathrm{~h}$ or more after the onset of anesthetic therapy (31). Three-month functional outcome was assessed via telephone interviews by a trained study assistant using Modified Rankin Scale (mRS), who was blind to the clinical data. A mRS $>3$ (severe disability and death) was considered as poor outcome, and a mRS $\leq 3$ (normal, slight and moderate disability) was considered favorable outcome.

\section{Statistics}

Univariate comparisons of categorical variables were performed using $\chi^{2}$-test analysis. For continuous variables, normal and non-normal distributions were distinguished by the ShapiroWilk test. The comparisons of normally distributed variables were performed using the Student $t$-test, and the comparisons of non-normally distributed variables were performed using the Mann-Whitney $U$-test. Age, gender, and potential risk factors with a significance level $<0.05$ in the univariate comparisons were included into univariate and multivariate (stepwise backward) logistic regression analyses to examine their associations with a certain outcome by estimating odds ratios (ORs) and associated confidence intervals (CIs). Two-sided $p \leqq 0.05$ were considered significant. Statistical analysis was performed with SPSS version 22 software (SPSS Inc., Chicago, IL, United States).

\section{RESULTS}

\section{Demographics and Clinical Features}

Between March 2008 and February 2018, 570 patients with acute encephalitis were admitted to N-ICU (Figure 1). Among them, a total of 94 patients with SE were included in this study. The median age of the study cohort was 26 years old (Table 1), and $55(58.5 \%)$ patients were male. The median time from onset to SE was 5 days, and the median time from onset to N-ICU admission was 11 days. Eighty-nine (94.7\%) patients had seizures before admission, and only eight (8.5\%) patients had a history of epilepsy. Most patients had unknown causes (42.6\%), followed by viral encephalitis (28.7\%), autoimmune (22.3\%), bacterial (4.3\%), cryptococcosis $(1.1 \%)$, and neurosyphilis $(1.1 \%)$.

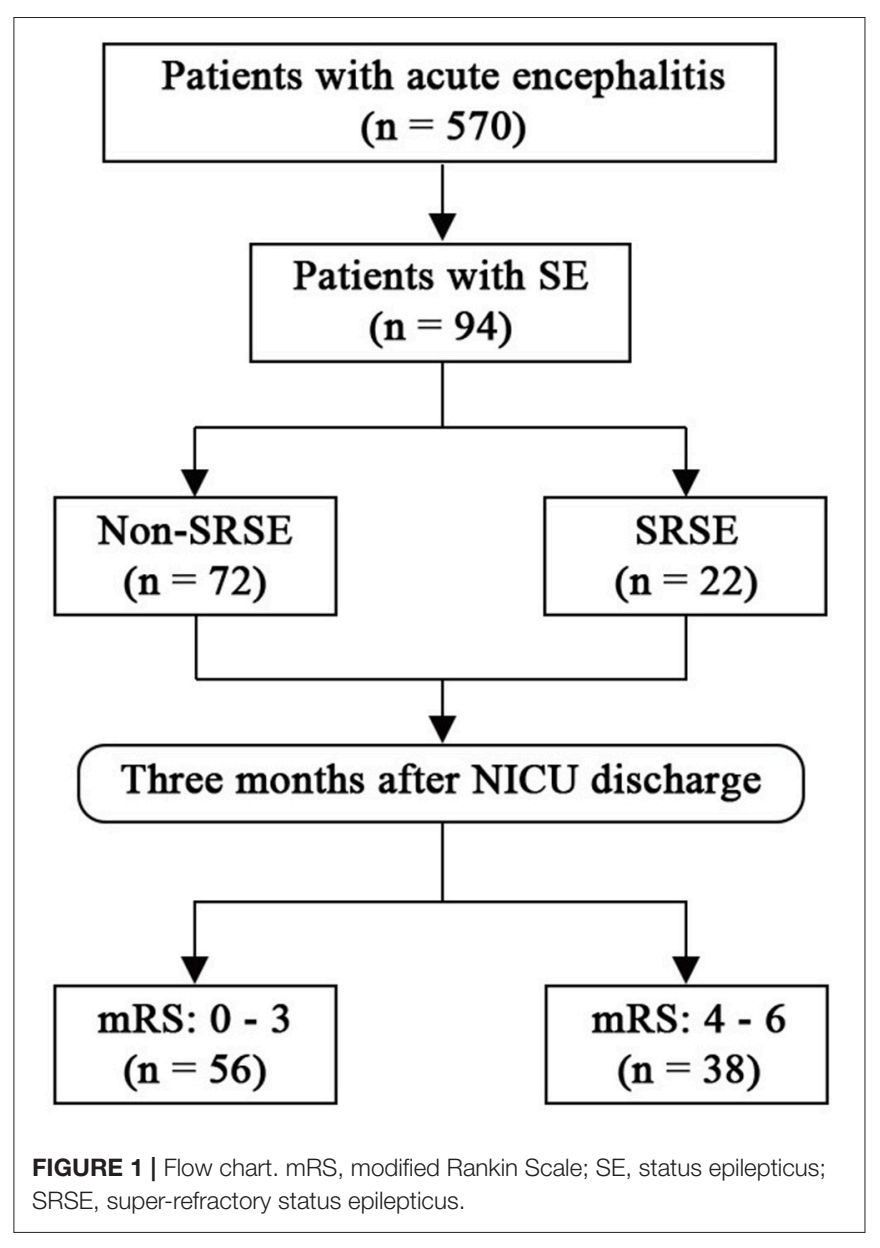

\section{Early Predictors for Progression to SRSE}

Forty-one (43.6\%) patients with SE due to acute encephalitis evolved into RSE, and 22 (23.4\%) patients evolved into SRSE. Patients with SRSE had significantly lower GCS score $(p=0.006)$, higher STESS $(p<0.001)$ and END-IT score $(p<0.001$; Table 1$)$. There were significantly more patients with MRI abnormalities on the cortex or hippocampus in SRSE group $(p=0.034)$. Results from multivariate logistic regression analysis (Table 2) showed that END-IT score $(p<0.001)$ and cortical/hippocampal abnormality on MRI $(p=0.002)$ were independent predictors for progression to SRSE. The cut-off point of 4 in END-IT score produced the optimal sum of sensitivity and specificity for the prediction of the progression to SRSE.

\section{NICU Management}

Table 3 showed the managements in N-ICU for all the patients with SE due to acute encephalitis, including RSE and SRSE cases. The length of EEG monitoring for the whole cohort was 46 (2881) hours, for RSE cases was 77 (47-171) hours, and for SRSE cases was 105 (69-274) hours. Forty-five (47.9\%) patients with SE due to acute encephalitis received CIVADs, and 22 (23.4\%) patients received CIVADs with more than 50\% PMD. Immune therapies were used in $25(26.6 \%)$ cases, tracheal intubation was 
TABLE 1 | Demographics and clinical characteristics of patients with status epilepticus associated with acute encephalitis.

\begin{tabular}{|c|c|c|c|c|}
\hline & Total $(n=94)$ & Non-SRSE $(n=72)$ & SRSE $(n=22)$ & $P$ value \\
\hline Age, year & $26(18-42)$ & $32(19-45)$ & $22(15-30)$ & 0.017 \\
\hline Male (\%) & 55 (58.5) & $44(61.1)$ & $11(50.0)$ & 0.355 \\
\hline Time from onset to SE, day & $5(3-11)$ & $7(3-14)$ & $5(3-7)$ & 0.290 \\
\hline Seizures before admission (\%) & $89(94.7)$ & $67(93.1)$ & $22(100.0)$ & 0.204 \\
\hline STESS & $4(3-5)$ & $4(3-4)$ & $5(4-5)$ & $<0.001$ \\
\hline END-IT score & $3(3-4)$ & $3(2-3)$ & $3(3-4)$ & $<0.001$ \\
\hline Encephalitis etiology (\%) & & & & 0.512 \\
\hline Viral & $27(28.7)$ & $22(30.6)$ & $5(22.7)$ & \\
\hline Bacterial & $4(4.3)$ & $4(5.6)$ & $0(0.0)$ & \\
\hline Unknown & $40(42.6)$ & $27(37.5)$ & $13(59.1)$ & \\
\hline NCSE in coma (\%) & $53(56.4)$ & $33(45.8)$ & 20 (90.9) & $<0.001$ \\
\hline Brain image (\%) & & & & 0.034 \\
\hline Normal & $34(36.2)$ & $25(34.7)$ & $9(40.9)$ & \\
\hline Cortical or hippocampal involvement & $27(28.7)$ & 17 (23.6) & $10(45.5)$ & \\
\hline Exclusively abnormalities in other areas* & $33(35.1)$ & $30(41.7)$ & $3(13.6)$ & \\
\hline
\end{tabular}

GCS, Glasgow coma scale; NCSE, nonconvulsive status epilepticus; NICU, neurological intensive care unit; SRSE, super-refractory status epilepticus; STESS, status epilepticus severity score. *Brain parenchyma except cortex and hippocampus.

Data presented as $n$ (\%) or median (interquartile range).

TABLE 2 | Logistic regression analysis for predictors of SRSE in acute encephalitis.

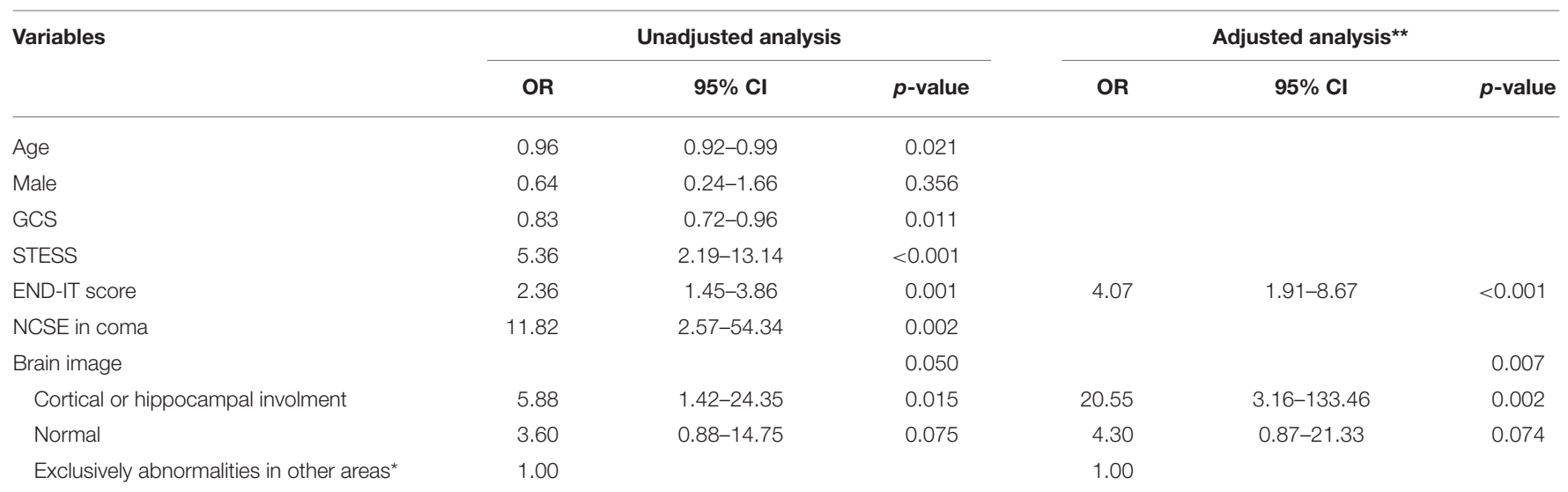

GCS, Glasgow coma scale; NCSE, nonconvulsive status epilepticus; SRSE, super-refractory status epilepticus; STESS, status epilepticus severity score. *Brain parenchyma except cortex and hippocampus. ${ }^{* *}$ Hosmer and Lemeshow Test: $p=0.935$.

used in $51(54.3 \%)$ cases, vasopressors were used in $32(34.0 \%)$ cases, and emergency resuscitation was used in $12(12.8 \%)$ cases.

\section{Responses to Antiepileptic Treatment}

Thirty-two (34.0\%) patients with SE due to acute encephalitis had seizures within $2 \mathrm{~h}$ after the initial use of CIVAD, and 16 (17.0\%) patients still had seizures within $2 \mathrm{~h}$ after the rate of CIVAD was raised to $>50 \%$ PMD. Breakthrough seizures occurred in
$35(37.2 \%)$ cases, and withdrawal seizures occurred in 30 (31.9) cases.

\section{Outcomes}

Forty-one (43.6\%) cases of SE in acute encephalitis were refractory status epilepticus (RSE), 22 (23.4\%) cases are SRSE. Thirty-eight $(40.4 \%)$ patients with SE due to acute encephalitis had a poor outcome 3 months after N-ICU discharge, 19 (46.4\%) 
TABLE 3 | NICU management and treatment responses of status epilepticus in acute encephalitis.

\begin{tabular}{lccc}
\hline & $\begin{array}{c}\text { SE } \\
(\boldsymbol{n}=\mathbf{9 4})\end{array}$ & $\begin{array}{c}\text { RSE* } \\
(\boldsymbol{n}=\mathbf{4 1})\end{array}$ & $\begin{array}{c}\text { SRSE } \\
(\boldsymbol{n}=\mathbf{2 2})\end{array}$ \\
\hline Length of EEG monitoring, h & $46(28-81)$ & $77(47-171)$ & $105(69-274)$ \\
Number of IV AEDs & $2(1-3)$ & $3(3-4)$ & $4(3-4)$ \\
Use of CIVADs (\%) & $45(47.9)$ & $41(100.0)$ & $22(100.0)$ \\
CIVAD >50\% PMD (\%) & $22(23.4)$ & $22(53.7)$ & $18(81.8)$ \\
Seizures within 2h after & $32(34.0)$ & $30(73.2)$ & $19(86.4)$ \\
CIVAD (\%) & $16(17.0)$ & $16(39.0)$ & $15(68.2)$ \\
Seizures within 2 h after & $35(37.2)$ & $33(80.5)$ & $21(95.5)$ \\
CIVAD >50\% PMD (\%) & $30(31.9)$ & $28(68.3)$ & $21(95.5)$ \\
Breakthrough seizures (\%) & $20(21.3)$ & $20(48.8)$ & $17(77.3)$ \\
Withdrawal seizures (\%) & $25(26.6)$ & $11(26.8)$ & $6(27.3)$ \\
CIVADs changed (\%) & $51(54.3)$ & $30(73.2)$ & $20(90.9)$ \\
Immune therapies (\%) & $32(34.0)$ & $19(46.3)$ & $15(68.2)$ \\
Tracheal intubation (\%) & $12(12.8)$ & $8(19.5)$ & $6(27.3)$ \\
Use of vasopressors (\%) & & & \\
Emergency resuscitation (\%) & & & \\
\hline
\end{tabular}

CIVADs, continuous IV anesthetic drugs; PMD, proposed maximal dose; RSE, refractory status epilepticus; SE, status epilepticus; SRSE, super-refractory status epilepticus. *Includes SRSE cases.

Data presented as $n$ (\%) or median (interquartile range).

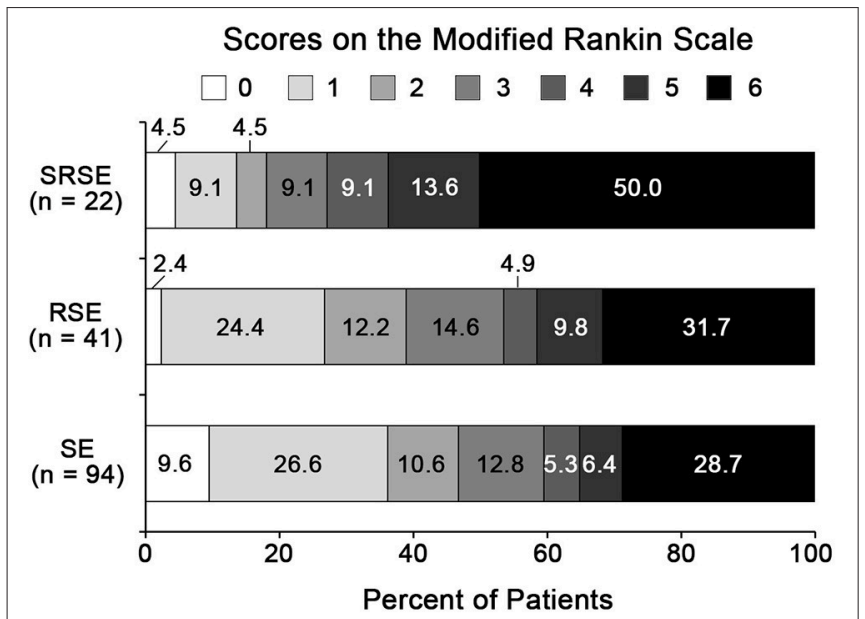

FIGURE 2 | Three-month functional outcomes of SE in acute encephalitis. 0, no symptoms; 1, no significant disability; 2, slight disability; 3, moderate disability; 4, moderately severe disability; 5 , severe disability; 6 , dead. RSE, refractory status epilepticus; SE, status epilepticus; SRSE, super-refractory status epilepticus.

RSE patients had a poor 3-month outcome, and 16 (72.7\%) SRSE patients had a poor 3-month outcome (Figure 2).

\section{Prognostic Factors for 3-Month Functional Outcome}

Table 4 showed that patients with a poor outcome had significantly less time from the onset of encephalitis to SE ( $p=$ $0.031)$, significantly higher STESS $(p=0.028)$ and END-IT scores $(p=0.001)$. Patients with a poor outcome were administered
TABLE 4 | Clinical characteristics of patients with favorable and unfavorable outcomes after status epilepticus associated with acute encephalitis.

\begin{tabular}{|c|c|c|c|}
\hline & mRS: 0-3 ( $n=56)$ & mRS: 4-6 $(n=38)$ & $P$-value \\
\hline Age, years & 25 (18-39) & $33(18-45)$ & 0.282 \\
\hline Male (\%) & $29(51.8)$ & $26(68.4)$ & 0.108 \\
\hline $\begin{array}{l}\text { Time from onset to NICU } \\
\text { admission, day }\end{array}$ & $11(7-23)$ & $10(6-21)$ & 0.685 \\
\hline Time from onset to SE, day & $7(3-14)$ & $5(1-9)$ & 0.031 \\
\hline $\begin{array}{l}\text { Seizures before admission } \\
\text { (\%) }\end{array}$ & $54(96.4)$ & $35(92.1)$ & 0.359 \\
\hline History of epilepsy (\%) & $5(8.9)$ & $3(7.9)$ & 0.860 \\
\hline GCS on admission & $9(6-12)$ & $7(4-12)$ & 0.188 \\
\hline STESS & $3(2-3)$ & $3(3-4)$ & 0.028 \\
\hline END-IT score & $3(3-4)$ & $4(3-5)$ & 0.001 \\
\hline NCSE in coma (\%) & $26(46.4)$ & $27(71.1)$ & 0.018 \\
\hline Abnormal MRI findings (\%) & $32(57.1)$ & $28(73.7)$ & 0.101 \\
\hline Number of IV AEDs & $2(1-3)$ & $3(1-4)$ & 0.031 \\
\hline Use of CIVADs (\%) & $24(42.9)$ & $21(55.3)$ & 0.237 \\
\hline CIVAD > 50\% PMD (\%) & $9(16.1)$ & $13(34.2)$ & 0.042 \\
\hline $\begin{array}{l}\text { Seizures within } 2 \mathrm{~h} \text { after } \\
\text { CIVAD (\%) }\end{array}$ & $16(28.6)$ & $16(42.1)$ & 0.174 \\
\hline $\begin{array}{l}\text { Seizures within } 2 \mathrm{~h} \text { after } \\
\text { CIVAD > 50\% PMD (\%) }\end{array}$ & $3(5.4)$ & $13(34.2)$ & $<0.001$ \\
\hline Breakthrough seizures (\%) & $17(30.4)$ & $18(47.4)$ & 0.094 \\
\hline Withdrawal seizures (\%) & $14(25.0)$ & $16(42.1)$ & 0.081 \\
\hline CIVADs changed (\%) & $5(8.9)$ & 15 (39.5) & $<0.001$ \\
\hline Immune therapies (\%) & $16(28.6)$ & $9(23.7)$ & 0.599 \\
\hline Tracheal intubation (\%) & $20(35.7)$ & $31(81.6)$ & $<0.001$ \\
\hline Use of vasopressors (\%) & $9(16.1)$ & $23(60.5)$ & $<0.001$ \\
\hline Emergency resuscitation (\%) & $1(1.8)$ & $11(28.9)$ & $<0.001$ \\
\hline
\end{tabular}

CIVADs, continuous IV anesthetic drugs; GCS, Glasgow coma scale; NCSE, nonconvulsive status epilepticus; NICU, neurological intensive care unit; PMD, proposed maximal dose; STESS, status epilepticus severity score. Data presented as $n$ (\%) or median (interquartile range).

with significantly more IV AEDs $(p=0.031)$. Significantly more patients had NCSE in coma $(p=0.018)$, CIVAD $>50 \%$ PMD $(p=0.042)$, seizures within $2 \mathrm{~h}$ after CIVAD $>50 \% \operatorname{PMD}(p$ $<0.001)$, CIVADs changed $(p<0.001)$, tracheal intubation $(p<0.001)$, the use of vasopressors $(p<0.001)$, emergency resuscitation $(p<0.001)$ in the poor outcome group. Multivariate logistic regression analysis identified that the recurrence of seizures within $2 \mathrm{~h}$ after CIVAD $>50 \% \operatorname{PMD}(p=0.044)$, tracheal intubation $(p=0.011)$, and emergency resuscitation $(p=$ 0.040 ) were independent risk factors for 3-month poor outcome (Table 5).

\section{DISCUSSION}

In this study, we investigated the values of brain MRI and EEG monitoring for the predictions of progression to SRSE and 3month functional outcome in SE due to acute encephalitis. Our data demonstrated that cortical or hippocampal abnormality on MRI and END-IT score independently predicted the progression to SRSE, and the recurrence of clinical or EEG seizures within $2 \mathrm{~h}$ 
TABLE 5 | Logistic regression analysis for three-month unfavorable outcome.

\begin{tabular}{|c|c|c|c|c|c|c|}
\hline \multirow[t]{2}{*}{ Variables } & \multicolumn{3}{|c|}{ Unadjusted analysis } & \multicolumn{3}{|c|}{ Adjusted analysis* } \\
\hline & OR & $95 \% \mathrm{Cl}$ & $p$-value & OR & $95 \% \mathrm{Cl}$ & $p$-value \\
\hline Age & 1.02 & $0.99-1.04$ & 0.230 & & & \\
\hline Male & 2.02 & $0.85-4.78$ & 0.110 & & & \\
\hline Time from onset to SE & 0.99 & $0.97-1.01$ & 0.412 & & & \\
\hline STESS & 1.98 & $1.08-3.62$ & 0.027 & & & \\
\hline END-IT score & 1.94 & $1.31-2.87$ & 0.001 & & & \\
\hline NCSE in coma & 2.83 & $1.18-6.80$ & 0.020 & & & \\
\hline CIVAD > 50\% PMD & 2.72 & $1.02-7.23$ & 0.045 & & & \\
\hline Number of IV AEDs & 1.57 & $1.10-2.25$ & 0.013 & & & \\
\hline Seizures within $2 \mathrm{~h}$ after CIVAD > 50\% PMD & 9.19 & $2.40-35.17$ & 0.001 & 4.52 & $1.04-19.68$ & 0.044 \\
\hline CIVADs changed & 6.65 & $2.16-20.50$ & 0.001 & & & \\
\hline Tracheal intubation & 7.97 & $2.98-21.36$ & $<0.001$ & 4.99 & $1.37-11.69$ & 0.011 \\
\hline Use of vasopressors & 8.01 & $3.05-21.02$ & $<0.001$ & & & \\
\hline Emergency resuscitation & 22.41 & $2.75-182.67$ & 0.004 & 9.80 & $1.11-86.47$ & 0.040 \\
\hline
\end{tabular}

${ }^{*}$ Hosmer and Lemeshow Test: $p=0.970$.

after the infusion rate of a single anesthetic drug $>50 \% \mathrm{PMD}$, the use of tracheal intubation, and the use of emergency resuscitation independently predicted 3-month poor outcome in patients with SE due to acute encephalitis.

SRSE is a life-threatening neurological emergency occurring in $4-16.9 \%$ of all cause SE $(10,32-37)$. The observed incidence rate of SRSE in our study of SE due to acute encephalitis was $23.4 \%$ which was much higher than the average incidence, and it was consistent with previous studies suggesting that encephalitis was the determinant of progression from SE to SRSE $(10,32)$. However, no particular etiology of encephalitis was found in our study to be associated with a higher incidence of SRSE.

Besides encephalitis, a lower premorbid mRS score and NCSE in coma were also indicated to be the independent predictors of SRSE (38). In our study, GCS, STESS, and END-IT score were chosen to assess the illness severity and investigated as the potential predictors of SRSE. GCS was initially designed to evaluate the level of consciousness. STESS includes consciousness, seizure type, age, and history of epilepsy. ENDIT score encompasses etiology (encephalitis or not), NCSE, diazepam resistance, brain image, and use of tracheal intubation. The inclusion of measurements regarding more aspects of illness might be the reason why END-IT score was the independent predictor of SRSE in SE due to encephalitis.

Cortical regions and hippocampus have been demonstrated to be associated with epileptogenesis (39-46). In patients with acute encephalitis, cortical lesions on neuroimaging imply a high risk of early-onset status epilepticus (9). Our study also proved the predictive value of neuroimaging and found that the abnormality in cortex or hippocampus was an early predictor for the progression to SRSE in SE due to acute encephalitis. Further studies are needed to investigate whether a more aggressive antiepileptic therapy will shorten the duration of SE and improve the outcome in those patients with a high risk of SRSE.

Compared to all cause RSE, patients with RSE due to acute encephalitis had higher rates of recurrent seizures within $2 \mathrm{~h}$ of the initial CIVAD treatment, breakthrough seizures, and withdrawal seizures (27). However, the recurrence of these seizures was not associated with a poor outcome. Only the recurrence of clinical or EEG seizures within $2 \mathrm{~h}$ after the initiation of a single CIVAD at a dose of more than half the proposed maximal dose predicted an unfavorable functional outcome at 3 months. The recurrent seizures under the CIVAD treatment are usually subtle or non-convulsive. Thus, continuous EEG monitoring not only plays an indispensable role in the monitoring and treatment of SE, but also contributes to the outcome prediction in SE due to acute encephalitis.

This study contained a larger sample size of SE due to acute encephalitis compared to previous studies, described the antiepileptic treatment responses at length, and firstly identified early predictors of SRSE in SE due to acute encephalitis. However, this study had a retrospective observational design and was conducted in a single tertiary care center. Moreover, because our hospital is one of the largest hospitals in northwest China, many patients were referred from other hospitals. Some patients might have not received a timely and sufficient anti-epileptic treatment initially. In this study, we followed the Chinese guidelines on the management of SE (15), which were consistent with the European guidelines about the proposed maximal dose of CIVADs (14), but the maximal dose of midazolam we used was lower than the suggestions proposed in American guidelines (47). So far the treatment with high-dose midazolam for refractory SE has not been widely performed in China, future studies are needed to be conducted in China to investigate and validate the effects of different infusion doses of midazolam in SE patients.

\section{CONCLUSIONS}

This study investigated the values of neuroimaging and continuous EEG in the multimodal predictions in SE due to acute encephalitis. Cortical or hippocampal abnormality on 
neuroimaging and END-IT score are independent predictors of SRSE. The recurrence of clinical or EEG seizures within $2 \mathrm{~h}$ after the infusion rate of a single CIVAD $>50 \%$ proposed maximal dose predicts a poor outcome at 3 months after NICU discharge.

\section{AUTHOR CONTRIBUTIONS}

FYu: Study concept and design, drafting of the manuscript, critical revision, statistical analysis, study supervision. FYa:

\section{REFERENCES}

1. Johnson RT. Acute encephalitis. Clin Infect Dis. (1996) 23:219-26. doi: 10.1093/clinids/23.2.219

2. Davison KL, Crowcroft NS, Ramsay ME, Brown DW, Andrews NJ. Viral encephalitis in England, 1989-1998: what did we miss? Emerg Infect Dis. (2003) 9:234-40. doi: 10.3201/eid0902.020218

3. Venkatesan A, Tunkel AR, Bloch KC, Lauring AS, Sejvar J, Bitnun A, et al. Case definitions, diagnostic algorithms, and priorities in encephalitis: consensus statement of the international encephalitis consortium. Clin Infect Dis. (2013) 57:1114-28. doi: 10.1093/cid/cit458

4. Granerod J, Ambrose HE, Davies NWS, Clewley JP, Walsh AL, Morgan D, et al. Causes of encephalitis and differences in their clinical presentations in England: a multicentre, population-based prospective study. Lancet Infect Dis. (2010) 10:835-44. doi: 10.1016/S1473-3099(10)70222-X

5. Thakur KT, Motta M, Asemota AO, Kirsch HL, Benavides DR, Schneider EB, et al. Predictors of outcome in acute encephalitis. Neurology (2013) 81:793-800. doi: 10.1212/WNL.0b013e3182a2cc6d

6. Singh TD, Fugate JE, Rabinstein AA. The spectrum of acute encephalitis causes, management, and predictors of outcome. Neurology (2015) 84:359-66. doi: 10.1212/WNL.0000000000001190

7. Sonneville R, Gault N, de Montmollin E, Klein IF, Mariotte E, Chemam S, et al. Clinical spectrum and outcomes of patients with encephalitis requiring intensive care. Eur J Neurol (2015) 22:6-16, el. doi: 10.1111/ene.12541

8. Spatola M, Novy J, Du Pasquier R, Dalmau J, Rossetti AO. Status epilepticus of inflammatory etiology a cohort study. Neurology (2015) 85:464-70. doi: 10.1212/WNL.0000000000001717

9. Sonneville R, Mariotte E, Neuville M, Minaud S, Magalhaes E, Ruckly S, et al. Early-onset status epilepticus in patients with acute encephalitis. Med (Baltimore) (2016) 95:e4092. doi: 10.1097/MD.0000000000004092

10. Chateauneuf AL, Moyer JD, Jacq G, Cavelot S, Bedos JP, Legriel S. Superrefractory status epilepticus: epidemiology, early predictors, and outcomes. Intens Care Med. (2017) 43:1532-4. doi: 10.1007/s00134-017-4837-6

11. Gao Q, Ou-Yang TP, Sun XL, Yang F, Wu C, Kang T, et al. Prediction of functional outcome in patients with convulsive status epilepticus: the END-IT score. Crit Care (2016) 20:46. doi: 10.1186/s13054-016-1221-9

12. Trinka E, Cock H, Hesdorffer D, Rossetti AO, Scheffer IE, Shinnar S, et al. A definition and classification of status epilepticus-report of the ILAE task force on classification of status epilepticus. Epilepsia (2015) 56:1515-23. doi: 10.1111/epi.13121

13. Meierkord H, Boon P, Engelsen B, Göcke K, Shorvon S, Tinuper P, et al. EFNS guideline on the management of status epilepticus. Eur J Neurol. (2006) 13:445-50. doi: 10.1111/j.1468-1331.2006.01397.x

14. Meierkord H, Boon P, Engelsen B, Gocke K, Shorvon S, Tinuper P, et al. EFNS guideline on the management of status epilepticus in adults. Eur J Neurol. (2010) 17:348-55. doi: 10.1111/j.1468-1331.2009. 02917.x

15. Neurocritical Care Group from Chinese Medical Association's Neurology Chapter. Chinese expert consensus for monitoring and management of adult patients with convulsive status epilepticus. Chin J Neurol (2014) 47:661-66.

16. Meierkord H, Holtkamp M. Non-convulsive status epilepticus in adults: clinical forms and treatment. Lancet Neurol. (2007) 6:329-39. doi: 10.1016/S1474-4422(07)70074-1
Study concept and design, critical revision, study supervision. RJ, WL, YJ, JZ: Acquisition, analysis, interpretation of data. WJ: Study concept and design, critical revision, obtained funding.

\section{FUNDING}

This study was funded by the Natural Science Foundation of China (grant number 81571262, WJ).

17. Kälviäinen R. Status epilepticus treatment guidelines. Epilepsia (2007) 48:99-102.

18. Glauser T, Shinnar S, Gloss D, Alldredge B, Arya R, Bainbridge J, et al Evidence-based guideline treatment of convulsive status epilepticus in children and adults report of the guideline committee of the american epilepsy society. Epilepsy Curr. (2016) 16:48-61. doi: 10.5698/1535-7597-16.1.48

19. Sutter R, Semmlack S, Kaplan PW. Nonconvulsive status epilepticus in adults - insights into the invisible. Nat Rev Neurol. (2016) 12:281-93. doi: 10.1038/nrneurol.2016.45

20. Rossetti AO, Logroscino G, Bromfield EB. A clinical score for prognosis of status epilepticus in adults. Neurology (2006) 66:1736-8. doi: 10.1212/01.wnl.0000223352.71621.97

21. Schwarz S, Bertram M, Schwab S, Andrassy K, Hacke W. Serum procalcitonin levels in bacterial and abacterial meningitis. Crit Care Med. (2000) 28:1828-32. doi: 10.1097/00003246-200006000-00024

22. Takahashi W, Nakada TA, Abe R, Tanaka K, Matsumura Y, Oda S. Usefulness of interleukin 6 levels in the cerebrospinal fluid for the diagnosis of bacterial meningitis. J Crit Care (2014) 29:693 e1-6. doi: 10.1016/j.jcrc.2014. 02.020

23. Marais S, Thwaites G, Schoeman JF, Török ME, Misra UK, Prasad K, et al. Tuberculous meningitis: a uniform case definition for use in clinical research. Lancet Infect Dis. (2010) 10:803-12. doi: 10.1016/S1473-3099(10)70138-9

24. Viallon A, Desseigne N, Marjollet O, Birynczyk A, Belin M, Guyomarch S, et al. Meningitis in adult patients with a negative direct cerebrospinal fluid examination: value of cytochemical markers for differential diagnosis. Crit Care (2011) 15:R136. doi: 10.1186/cc10254

25. Viallon A, Zeni F, Lambert C, Pozzetto B, Tardy B, Venet C, et al. High sensitivity and specificity of serum procalcitonin levels in adults with bacterial meningitis. Clin Infect Dis. (1999) 28:1313-6. doi: 10.1086/514793

26. Graus F, Titulaer MJ, Balu R, Benseler S, Bien CG, Cellucci T, et al. A clinical approach to diagnosis of autoimmune encephalitis. Lancet Neurol. (2016) 15:391-404. doi: 10.1016/S1474-4422(15)00401-9

27. Claassen J, Hirsch LJ, Emerson RG, Mayer SA. Treatment of refractory status epilepticus with pentobarbital, propofol, or midazolam a systematic review. Epilepsia (2002) 43:146-53. doi: 10.1046/j.1528-1157.2002. 28501.x

28. Yuan F, Yang F, Li W, Yang X, Gao Q, Bi L, et al. Nonconvulsive status epilepticus after convulsive status epilepticus: clinical features, outcomes, and prognostic factors. Epilepsy Res. (2018) 142:53-7. doi: 10.1016/j.eplepsyres.2018.03.012

29. Claassen J, Albers D, Schmidt JM, De Marchis GM, Pugin D, Falo CM, et al. Nonconvulsive seizures in subarachnoid hemorrhage link inflammation and outcome. Ann Neurol. (2014) 75:771-81. doi: 10.1002/ana.24166

30. Rossetti AO, Lowenstein DH. Management of refractory status epilepticus in adults: still more questions than answers. Lancet Neurol. (2011) 10:922-30. doi: 10.1016/S1474-4422(11)70187-9

31. Shorvon S, Ferlisi M. The treatment of super-refractory status epilepticus: a critical review of available therapies and a clinical treatment protocol. Brain (2011) 134:2802-18. doi: 10.1093/brain/awr215

32. Jayalakshmi S, Ruikar D, Vooturi S, Alladi S, Sahu S, Kaul S, et al. Determinants and predictors of outcome in super refractory status epilepticus-a developing country perspective. Epilepsy Res. (2014) 108:1609-17. doi: 10.1016/j.eplepsyres.2014.08.010 
33. Tian L, Li Y, Xue X, Wu M, Liu F, Hao X, et al. Super-refractory status epilepticus in West China. Acta Neurol Scand. (2015) 132:1-6. doi: 10.1111/ane.12336

34. Kantanen AM, Reinikainen M, Parviainen I, Ruokonen E, AlaPeijari M, Backlund $\mathrm{T}$, et al. Incidence and mortality of superrefractory status epilepticus in adults. Epilepsy Behav. (2015) 49:131-4. doi: 10.1016/j.yebeh.2015.04.065

35. Delaj L, Novy J, Ryvlin P, Marchi NA, Rossetti AO. Refractory and superrefractory status epilepticus in adults: a 9-year cohort study. Acta Neurol Scand. (2017) 135:92-9. doi: 10.1111/ane.12605

36. Strzelczyk A, Ansorge S, Hapfelmeier J, Bonthapally V, Erder MH, Rosenow F. Costs, length of stay, and mortality of super-refractory status epilepticus: a population-based study from Germany. Epilepsia (2017) 58:1533-41. doi: 10.1111/epi.13837

37. Misra UK, Kalita J, Dubey D. A study of super refractory status epilepticus from India. Front Neurol. (2017) 8:636. doi: 10.3389/fneur.2017.00636

38. MadŽar D, Knappe RU, Reindl C, Giede-Jeppe A, Sprügel MI, Beuscher V, et al. Factors associated with occurrence and outcome of super-refractory status epilepticus. Seizure (2017) 52:53-9. doi: 10.1016/j.seizure.2017.09.003

39. Kim YJ, Kim JY, Ko AR, Kang TC. Reduction in heat shock protein 90 correlates to neuronal vulnerability in the rat piriform cortex following status epilepticus. Neuroscience (2013) 255:265-77. doi: 10.1016/j.neuroscience.2013.09.050

40. Hirotsu C, Matos G, Tufik S, Andersen ML. Changes in gene expression in the frontal cortex of rats with pilocarpine-induced status epilepticus after sleep deprivation. Epilepsy Behav. (2013) 27:378-84. doi: 10.1016/j.yebeh.2013.02.024

41. Mori F, Tanji K, Miki Y, Nishijima H, Baba M, Kurotaki H, et al. Status epilepticus associated with extensive axonal swelling in the unilateral cerebral cortex and hippocampus. Neuropathol Appl Neurobiol. (2012) 38:387-90. doi: 10.1111/j.1365-2990.2011.01223.x

42. Chen S, Fujita S, Koshikawa N, Kobayashi M. Pilocarpine-induced status epilepticus causes acute interneuron loss and hyper-excitatory propagation in rat insular cortex. Neuroscience (2010) 166:341-53. doi: 10.1016/j.neuroscience.2009.12.023

43. Dubey D, McRae PA, Rankin-Gee EK, Baranov E, Wandrey L, Rogers S, et al. Increased metalloproteinase activity in the hippocampus following status epilepticus. Epilepsy Res. (2017) 132:50-8. doi: 10.1016/j.eplepsyres.2017.02.021

44. Salo RA, Miettinen T, Laitinen T, Grohn O, Sierra A. Diffusion tensor MRI shows progressive changes in the hippocampus and dentate gyrus after status epilepticus in rat - histological validation with Fourier-based analysis. Neuroimage (2017) 152:221-36. doi: 10.1016/j.neuroimage.2017.03.003

45. Wyatt-Johnson SK, Herr SA, Brewster AL. Status epilepticus triggers time-dependent alterations in microglia abundance and morphological phenotypes in the hippocampus. Front Neurol. (2017) 8:700. doi: 10.3389/fneur.2017.00700

46. Cai X, Long L, Yang L, Chen Z, Ni G, Qin J, et al. Association between mossy fiber sprouting and expression of semaphorin-3f protein in dentate gyrus of hippocampus in lithium-pilocarpine-induced status epilepticus mouse model. Neurol Res. (2016) 17:1-6. doi: 10.1080/01616412.2016.1243639

47. Brophy GM, Bell R, Claassen J, Alldredge B, Bleck TP, Glauser T, et al. Guidelines for the evaluation and management of status epilepticus. Neurocrit Care (2012) 17:3-23. doi: 10.1007/s12028-012-9695-z

Conflict of Interest Statement: The authors declare that the research was conducted in the absence of any commercial or financial relationships that could be construed as a potential conflict of interest.

Copyright (C) 2018 Yuan, Yang, Jia, Li, Jiang, Zhao and Jiang. This is an open-access article distributed under the terms of the Creative Commons Attribution License (CC $B Y)$. The use, distribution or reproduction in other forums is permitted, provided the original author(s) and the copyright owner(s) are credited and that the original publication in this journal is cited, in accordance with accepted academic practice. No use, distribution or reproduction is permitted which does not comply with these terms. 